\title{
La literatura española en La casa de cartón ${ }^{1}$.
}

\author{
Miguel Angel Rodríguez Rea \\ Departamento Académico de Literatura
}

\begin{abstract}
Como se sabe, la crítica en el Perú sobre la literatura española se inicia - de manera indeleble en la época colonial, en 1662, con el Apologético a favor de Luis de Góngora. Desde esa entonces, podemos seguir la ruta de todos aquellos interesados en resaltar los valores de una literatura que se asentó en nuestro medio luego de la Conquista.

Cuando se inicia el siglo XX, José de la Riva-Agüero enlazará la tradición literaria nuestra con la española, al afirmar enfáticamente que somos una prolongación de la literatura de la Península ${ }^{2}$. Esto como se supone tuvo consecuencias en el cuerpo de la crítica de aquel tiempo. Se establecerá, lo que yo denomino en un librođe hace unos años, el debate sobre la literatura peruana $^{3}$. Debate que tendyá în arco đẹ tiempoeque va de 1905 -año de la tesis de bachiller de Riva-Agüero- a 1928 -año de la aparición de "El proceso de la literatura" que José Carlos Mariátegui incluye en sus 7 ensayos. Pasando en este periplo por las tesis doctoral de José Gálvez y de bachiller de Luis Alberto Sánchez, que son el tema central en estas proposiciones académicas.
\end{abstract}

1 Texto leído el 17 de noviembre del 2000 en el Coloquio en torno de Martín Adán, organizado por la Biblioteca Central de la Pontificia Universidad Católica del Perú.

2 José de la Riva-Agüero y Osma, Carácter de la literatura del Perí independiente. Lima: Pontificia Universidad Católica del Perú, 1962: [261].

3 Miguel Angel Rodríguez Rea, La literatura peruana en debate: 1905-1928. Lima: Ediciones Antonio Ricardo, 1985. 
Etapa de gran importancia en el desarrollo de la crítica, pues aquí se discute de manera definitiva el perfil que ha de tener la literatura peruana. En todo caso, la búsqueda de elementos que distingan lengua, personajes y símbolos capaces de cotejarse con la realidad viva.

Es así que la presencia de estos tratadistas resulta necesaria, pues ellos, a partir de la tradición literaria existente, delínean el espectro de una literatura que suponen se producirá. En realidad, lo que intentan es ofrecer un marco de referencia para comprender la literatura que en esos momentos circulaba, y la que los lectores podían esperar ver en los próximos libros.

No reseñaré (pues no es materia de esta exposición) los planteamientos puestos en discusión, sólo agregaré que todos ellos parten de una idea de la literatura peruana teniendo como telón de fondo una realidad que concerta lo actual y lo pasado, lo nacional y lo universal, y que todo esto debe conciliarse en la ficción, la que debe reflejarse - como lo grafica Sánchez- en "un producto o resultante de las fuerzas del pasado y de las aspiraciones del porvenir. Las manos de los que se fueron se juntan, cual en la frase de Maeterlinck, con las de los que van a llegar"'4.

El caso de este debate resulta peculiar, ya que se lleva a cabo durante casi tres décadas. Periodo en que la literatura y el arte en el Perú están sujetos a innovaciones técnicas y temáticas; donde se eliminan muchas ataduras éticas y estéticas, etc. De modo que cada planteamiento hurga en la tradición nuestra y en la occidentalpara establecer una Titeratura que resista cualquier cambio en la sociedad o en la historia.

La aparición de La casa de cartón en 1928, no sólo hace patente la culminación del proceso de asimilación de la vanguardia artística europea, sino que también va a registrar su participación en este debate sobre el carácter de la literatura peruana. No será una propuesta académica propiamente dicha, pues, como se sabe, su tesis doctoral, De lo barroco en el Perú, data de diez años más tarde: 1938. Será pues en este volumen de narración singular en el que fije su punto de vista al respecto.

Miguel Angel Rodríguez Rea, Op. cit: 67. 
Y será precisamente al hablar de literatura española. Una literatura que no estuvo ajena a sus intereses de lector precoz y exigente. A pesar de que la crítica ha establecido sus deudas con literaturas en otras lenguas. El mismo Martín Adán lo señala de manera rotunda:

Nosotros leíamos a los españoles, a nadie más que a los españoles. Sólo Raúl hojeaba libros franceses, ingleses, italianos, en traducciones de un tal Pérez, o de un tal González de Mesa, o de un tal Zapata y Zapater. Así nosotros teníamos, a pesar de Belda y Azorín, una imagen pintoresca de la literatura universal ${ }^{5}$.

Más adelante subrayará esta predilección, hasta cierto punto condicionada por la época y la circulación de obras de autores españoles decimonónicos, de gran lectoría por lo menos en Lima, como puede comprobarse con las noticias de ellos y sobre ellos en las revistas Variedades y Mundial:

Nosotros, menos Raúl, nos ateníamos a la olla podrida literaria española y americana. Porque, como en la Ínsula Barataria, es manjar de canónigos y ricachones 6

Un contemporáneo suyo, compañero de clase y de ruta literaria, Emilio Adolfo Westphalen, corroborará este testimonio de lecturas:

Entre los compañeros de clase empezaron a circular otras obras

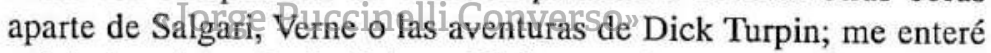
así de la existencia de Balzac, Dickens y algunos novelistas rusos de fines de siglo. El arco de mis intereses se fue ampliando por influencia de dos condiscípulos: Estuardo Núñez y el que más adelante adoptaría por nombre Martín Adán, cuyas normas de evaluación eran particularmente exigentes para su edad. Ignoro qué orden y concierto habían dispuesto ellos para sus lecturas. Las mías se acumularon como vinieran: autores antiguos y modernos, cuento, novela, novela y teatro, ensayo y poesía, los clásicos españoles

5 Citamos por la siguiente edición: Martín Adán, La casa de cartón, seguida por Varia invención. Edición e introducción de Ricardo Silva-Santisteban. Lima: Adobe Editores, 2000: 61 .

6 Ibíd.: 62 . 
en toda la gama, desde el Poema del Cid y el Arcipreste hasta Larra, Espronceda y Moratín, la generación del 98 completa, Ortega y sus discípulos, Gómez de la Serna, Gabriel Miró, mezclados con traducciones de Baudelaire, Flaubert, Nerval, Stendhal, France, Giradoux, Morand $[\ldots]^{7}$.

Muchos autores de estas lecturas de estudiante secundario, que rememora vivamente Westphalen aparecen en las páginas de La casa de cartón. Ya que son la lectura obligada de la iniciación literaria de la época. Algo más: en este recinto el día de ayer el Dr. Carlos Eduardo Zavaleta nos ha ilustrado magistralmente, por ejemplo, cómo la influencia de Gómez de la Serna es palpable en la escritura de los Poemas Underwood, incluidos en este libro.

¿Por qué esa incisión irreverente a una literatura de la cual Martín Adán es deudor? Creemos que es por el deseo de dejar sentado que la literatura española se la puede leer, asimilar, pero no con ello se puede seguir escribiendo como una prolongación de ella. Esto en una clara alusión al juicio que José de la Riva-Agüero estampara en su tesis de 1905 . Por eso dedicará una extensa y enjuiciada enumeración de los autores que más han tocado su sensibilidad adolescente:

Vengan los confidentes asexuales de don Jacinto Benavente, con barba en punfa, yłentres parabóliços y pantalones de fantasía; sus hadas, que saben de las costumbres de la buena sociedad; sus adúlteras por mandato del confesor; sus vidas perfectamente humanas e inútiles; sus morales centrípetas; sus conversaciones cursis, todo lo de Benavente. Y venga la literatura de Fernán Caballero, literatura credulona y bienaventurada, con licencia eclesiástica. Y la de Pardo Bazán, que huele a ropero de vieja con vagos efluvios de tomillo, llena de pecados que no llegan a cometerse -ipiadosa intención la de la escritora!-. Y la acatarrada y bravía de Pereda, con sus muchachas severas, sombrías, ceñudas, que se dan al prójimo por amor de Dios. Y la de Pérez Galdós, práctica y peligrosa, con tísicos y locos y criminales y apestados, pero que el lector ve

Emilio Adolfo Westphalen, "Poetas en la Lima de los años treinta", en Emilio Adolfo Westphalen y Julio Ramón Ribeyro, Dos soledades. Lima: Instituto Nacional de Cultura, 1974: 25. 
de lejos sin peligro. Y la de Maeztu, tabla de logaritmos que huele a agua de colonia y en la que cabe todo como en un saco de mano de Manchester, todo condensado, por supuesto, llena de guarismos, digna como una solterona inglesa. Y la de Camba, diálogo de ferrocarril con un joven sin familia, sin empleo y sin filosofías. $Y$ la del padre Coloma, llena de ángeles prudentes y escamados que no dejan la cítara ni un momento, y de cortesanas de buena índole, y de consejos a los aristócratas católicos. Y las digresiones de Baroja, y los maitines de Azorín, y las vísperas de Valle-Inclán, y las noches de Zamacois. Todo, todo, así, como venga, como caiga, pero $\sin$ inhumanidades... ${ }^{8}$

Un verdadero catálogo para el lector menos avisado. Este espíritu iconoclasta que disecciona con lenguaje profano autores de diversos géneros, no expresa sino la arrogancia que da el ser joven y el exigir una nueva literatura. Una literatura sin inhumanidades. La literatura española había perdido vitalidad para esta generación, que vive el cambio de referencias artísticas locales y foráneas. Una literatura que rescate la vida, la circunstancia, un mundo donde "[c]ada poeta expres[e] un dilema: el suyo y el de su tiempo".

Páginas más adelante, đedicará un buen número de líneas al escritor catalán Eugenio D’Ors, quien se convierte en la estrategia narrativa de Adán, en un personaje que debe realizar un acto decisivo:

Eugenio D'Ors, distifiguidol filósefo demînico, puede escribir su vida, la de Sergio o la suya propia, con santa esperanza de averiguar con certeza por qué se metió a fraile un muchacho que tenía los ojos de puerco y que mentía como ninguno. Y hasta podría D'Ors relatarnos de antemano su muerte -la de Sergio- bajo un crucifijo grande y cruel como la misma muerte, cogido él de una palabra tan simple de soledad y con toda la mañana en el judas de la celda. Y podría añadir gordas sutilezas a la sencillez de la muerte de un fraile de barbas viejas que alguna vez fue joven y sexualísimo. ¡Oh, qué libro maravilloso podría hacer Eugenio D’Ors con la vida y la muerte de Sergio! ¡Cómo conviene a una vida inmotivada y

8 Martín Adán, Op. cit: 62-63.

9 Emilio Adolfo Westphalen, Op. cit.: 46. 
estúpida, la filosofía bien plantada, buena moza, rica de ovarios tan salerosa, tan ingenuaza, tal catalana, del Glosador! Me parece estar leyéndole: “...y así... Pero examinemos, Glosador, y que el amor no nos arrastre... Medir... Comparar...". Pero, no sé por qué, yo creo de vez en cuando que Sergio no murió nunca; que, a la hora de morir, él hará el muerto; que se dejará enterrar y que, a los dos días, se desenterrará él mismo y volverá a Lima a mentir del convento y a principiar vida nueva. Ojalá sea así... Pero el libro de Eugenio D'Ors ya no podrá escribirse, y yo no podría llegar a saber nunca cómo era Sergio ${ }^{10}$.

Anotaré dos breves referencias que deseo comentar, y que muestran una recepción que se condice con las alusiones extensas ya antes señaladas. La primera ofrece una visión casi banal de un clásico del Siglo de Oro: fray Luis de León:

Mi tercer amor tenía los ojos lindos, y las piernas muy coquetas, casi cocotas. Hubo que leet a Fray Luis de León, y a Carolina Invernizzio ${ }^{11}$.

Una indudable desacralización de este poeta del Renacimiento español, ya que se le asocia a una aventura con-una "[p]eregrina muchacha...", que llegó a ser "casi [... Bamante" del personaje principal de la narración.

La segunda tiene quever con un tópico clásico de la literatura castellana medieval: la vida como un río:

¡Ah, Catita!, la vida no es un río que corre: la vida es una charca que se corrompe ${ }^{12}$.

Una inobjetable reformulación de los símbolos de esta literatura. Además de consignar en esta sentencia una de las más caras aristas de su poética, de estirpe renacentista: el indetenible deterioro de la naturaleza humana.

\footnotetext{
10 Martín Adán, Op. cit: $86-87$.

11 Ibíd.: 34 .

12 Ibíd.: 82 .
} 
Un texto suyo sobre la literatura española aparecerá un año después de publicada La casa de cartón. Será en la revista Letras, y lleva por título "El demonio español del siglo XVI"13, y no es sino un intento interpretativo de la protagonista de La Celestina. La manera cómo procede a enfocar el asunto, es el mismo que hallaremos en su tesis doctoral: discurso crítico subjetivo, "nunca métodico".

¿Por qué afirmamos que Martín Adán participa en este debate? Porque era una preocupación generacional. Su contacto con Mariátegui hubo de hacerlo consciente de esta perspectiva. Y esto lo constatamos cuando inicia De lo barroco en el Perú, tesis doctoral de 1938 donde señala:

Fruto de largo leer y releer, casi nunca metódico ni oportuno, estas páginas habré de leerlas con toda la inevitable vacilación de mi inseguridad, sobrecogido tanto del motivo como de la circunstancia. Donde se oyó no hace tantos años como para olvidarlo, lo que sobre literatura del Perú dijeron Riva-Agüero y Gálvez y otros, mi voz ha de procurar más el debido diapasón que el rico sentido ${ }^{14}$.

Como se advierte, para él están frescos los trabajos de Riva-Agüero y José Gálvez sobre el proceso literario peruano. Vale decir que esta tesis, para un estudio posterior, debe entendérsela en el contexto de esta discusión que abarca, como lo dijimos, casi tres décadas. Tesis escrita al calor del cambio de ideas, hechos y obras que dieron nueva configuración a la cultura peruana. "Jorge Puccinelli Converso"

Que Martín Adán utilice la ficción como tribuna para el intercambio de opiniones, no debe sorprendernos en absoluto, por cuanto la estética vanguardista establece que los géneros literarios ya no se sujetan al canon aristotélico. Esto es, las fronteras entre géneros no existen. Existe la voluntad de mostrar lo vital, lo que da ánimo de vida. Y si para dotar en el lector ese ánimo es

13 Rafael de la Fuente Benavides, "El demonio español del siglo XVI", Letras, № 1, 1929: 175-177. En realidad, este texto es un trabajo del curso de Literatura Castellana que tenía a su cargo Raúl Porras Barrenechea en la Universidad de San Marcos. Se publicó sobre el mismo tema con los de otros alumnos, siendo el de Martín Adán el más extenso de todos.

14 Rafael de la Fuente Benavides, De lo barroco en el Perú. Prólogo de Luis Alberto Sánchez. Lima: Universidad Nacional Mayor de San Marcos, 1968: 13. Véase asimismo una informada síntesis y comentario a esta tesis: David Sobrevilla, "De lo barroco en el Perú de Martín Adán", Lienzo, $\mathrm{N}^{2} 19,1998$ : 305-356. 
necesario suprimir esos límites, como el que cada género señalaba, se hace. Porque al fin y al cabo (piensan los vanguardistas) esas barreras son convencionales, por lo tanto el beneficio para la ficción en vez de aminorar se incrementa.

Martín Adán en La casa de cartón ofrece un doble servicio a las letras peruanas. Por un lado, recoge y cimenta la aventura vanguardista, lo cual hace que la prosa adquiera un rango cosmopolita, como ya lo había trazado Eguren y redimensionado Vallejo en la poesía. Por otro, su opinión sobre cómo hacer literatura nueva en el Perú: cancelando toda huella hispánica que no se condiga con los nuevos tiempos. La vida antes que el arte. Por eso Gómez de la Serna será un modelo que lo sentirá vivaz, contemporáneo, imaginativo, con solvencia de ser una fuente para la literatura del futuro.

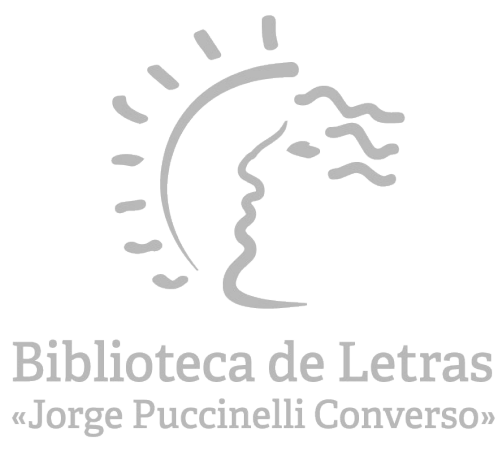

